\title{
NCI CTEP SDC Vascular Tumor, Miscellaneous Sub-Category Terminology
}

National Cancer Institute

\section{Source}

National Cancer Institute. NCI CTEP SDC Vascular Tumor, Miscellaneous Sub-Category

Terminology. NCI Thesaurus. Code C103096.

Vascular Tumor, Miscellaneous is an NCl Cancer Therapeutic Evaluation Program (CTEP) Simplified Disease Classification (SDC) category used to organize cancer-related disease coding that harmonizes with and supports reporting based on the global standard Medical Dictionary for Drug Regulatory Reporting (MedDRA) terminology. 